\title{
Risk management in corporate governance
}

\author{
Adrian-Cosmin CARAIMAN \\ West University of Timisoara, Timisoara, Romania \\ Adrian_Caraiman@Yahoo.Com \\ Dorel MATES \\ West University of Timisoara, Timisoara, Romania \\ Dorel.Mates@E-Uvt.Ro
}

\begin{abstract}
In this paper I want to present the place and role of risk management within an organization in corporate governance. Thus, the risk management of an organization consists of defining the risk, identifying and evaluating the impact and probability of materialization and, subsequently, establishing appropriate ways to manage the significant risks. According to some authors, the risk management of an organization is among the newcomers in the context of the concept of corporate governance, which brings a holistic perspective, as an integrating factor of the parts of a whole, which is the organization. At the same time, it can be emphasized that, according to the standards regarding strategic risk management, risk management should become an integrated part of the way any organization works; and in other ideas, being the basis of management approaches, it should not be separated from the daily activities of any organization. In corporate governance, in any entity, risk management is necessary because both in the company and in the environment in which it operates, there are uncertainties about the nature of the threats in achieving the objectives, or the nature of the opportunities. Any manager must pose the problem of managing the threats, because, otherwise, not reaching their objectives, they would be disqualified, or to take advantage of the opportunities for the benefit of the organization, proving their efficiency. If uncertainty is an everyday reality, then the reaction to uncertainty must become a permanent concern.
\end{abstract}

Keywords: risk, risk management, corporate governance, organization, uncertainties.

\section{Introduction}

Each public entity is obliged to systematically overview, at least once a year, the risks related to the conduct of its activities, to draw up appropriate plans in the direction of limiting the possible consequences of these risks and to appoint responsible persons for the application of those plans.

Under corporate governance, under any entity, risk management is necessary because both in the company and in the field in which it acts, there are uncertainties of the nature of threats in the achievement of objectives, or the nature of opportunities. Any manager must consider the way of managing the threats, because otherwise, not touching its objectives, it would disprove itself, or to use the opportunities for the benefit of the organization, proving its effectiveness. If uncertainty it is a daily reality, then the reaction to uncertainty must become a permanent concern.

\section{Literature review}

The risk-based decision has always been important in business. Enterprise risk management is the latest approach to risk management faced by an organisation from the view of a system (Wu, Olson, Dolgui, 2015), probably becoming the main objective of the strategic management of organisations, mainly due to multiple factors - the aversion of representative personel to uncertainty, the volatility of the current market and the mandates of compliance, as the authors said Arnold, Benford, Canada, Sutton (2015). 
The risk management of an organisation is to define the risk, identification and assessment of the impact and likelihood of materialisation and subsequently laying down appropriate ways of managing significant risks (Ghiţă, 2008, p. 239)

As the author said, the risk management of an organization is among new arrived in the context of the concept of corporate governance, which brings a holistic perspective, as the integral factor of the parts of a whole, which is the organization. So was Oliva (2016) mentioning, that the enterprises risk management was a recurring theme on the organisations' daily issues and as Fraser\&Simkins (2016) said, was generally recognised as an expectation of good management and good corporate governance. Moreover, as the authors of Bromiley, McShane, Nair, Rustambekov (2015) said, risk management suggests integrated management of all the risks faced by an organisation and which inherently require alignment of risk management with corporate governance and strategy, which can lead, as the authors claim, to the conclusion that a critical review of risk management research allows us to identify certain limitations and shortcomings that management specialists are more entitled to solve them.

With regard to the above authors Gordon, Loeb, Tseng (2009) come up with a very plausible point of view when a paradigm shift has occurred in recent years in terms of how organisations consider risk management; the tendency being a holistic view of risk management, which implies, we may add- in general terms, an "idealistic metaphysical conception that supports the principle of the whole of the parties and its irreductible ness to the sum of the component elements ( $<$ fr. holisme)". As the authors argue this holistic approach to managing an organisation's risk is commonly referred to as enterprises risk management (ERM). Indeed, the authors argue, there is growing support for the general argument that organisations will improve their performance by using the concept of risk management. The main argument being that the corespondence between risk management and the performance of organizations depends on the appropriate match between risk management and the following five factors affecting an organization, namely: environmental uncertainty, competition in industry, organization expansion, organisation complexity and management board monitoring. In conclusion, the authors mention that organisations should consider implementing a risk management system together with contextual variables around the organisation; and in addition, as Brossman (2016) claims, a proactive risk strategy should be managed at the same level throughout the organisation.

\section{Methodology}

In this article we aim to make certain conceptual limitations on the notion of risk management in corporate governance and to identify the stages that are going through in the conduct of the risk management process.

In corporate governance, in any entity, risk management is necessary because both in the company and in the environment in which it acts, there are uncertainties of the nature of threats in achieving objectives, or the nature of opportunities.

Any manager must question, on the one hand, to manage threats, because otherwise by not achieving his goals, would disqualify, or, on the other hand, to capitalise on opportunities for the benefit of the organization, proving his efficiency. If uncertainty is a daily reality, then the reaction to uncertainty must also become a permanent concern.

Our work presents a positive and at the same time constructive view on risk management in corporate governance. To achieve the purpose and objectives of the research we have proposed a descriptive research of the concepts in the specific literature. 
Through qualitative research we analyze the conceptual framework on risk management in corporate governance. Thus, we will not neglect the method of observation, which will gradually outline as the main method used for data collection and include both passive observations, namely spontaneous ones, made by chance, and the remarks caused, necessary verifying an idea.

In order to conduct research on risk management in corporate governance, we aim to

PICBE | 184 consider both the theoretical and applicative component by using:

-methods of research (collection, processing and interpretation of data)

-research techniques (bibliographical selection, data synthesizing study)

-research processes (reading, gathering, building and synthesizing data).

\section{Results and discussions}

The risk management of an organisation is to define the risk, identification and assessment of the impact and likelihood of materialisation and subsequently laying down appropriate ways of managing significant risks (Ghiţă, 2008, p. 239)

As the author said, the risk management of an organization is among new arrived in the context of the concept of corporate governance, which brings a holistic perspective, as the integral factor of the parts of a whole, which is the organization.

In the same way, quoting Treasury, Ghiţă $(2008$, p. 242) underlines that, according to standards on strategic risk management, risk management should become an integral part of how any management approaches should not be separated from the organization's daily activities.

Enterprise Risk Management focuses on developing, placing risk management at the center of an organization's strategic activities, and risks are treated both as exposures to be managed, as well as opportunities to exploit. (Farrell\&Gallagher, 2019)

In România each public entity is obliged to systematically overview, at least once a year, the risks related to the conduct of its activities, to draw up appropriate plans in the direction of limiting the possible consequences of these risks and to appoint responsible persons for the application of those plans.

Moreover, understanding the making of knowledge in state-owned enterprises (SOEs) is an ever-growing problem in academic debate and on the political agenda; but, as Landoni (2020) says, there is still a comprehensive theory missing, despite the large number of research published so far. Thus, as the author states, there is a lack of a new theoretical framework for creating knowledge in state-owned enterprises, by studying innovation and from the perspective of entrepreneurial company theory and knowledge management theory, which together provides new perspectives explaining the factors enabling innovation in state-owned enterprises and public entities. These factors are managerial autonomy and government coordination. In this respect, as the author considers, theoretical development is important, as it considers state-owned enterprises as public firms and entities, a dual nature that combines the advantages of state ownership and corporate governance.

In the context of the performance of an entity's activity is indicated by a technique for measuring the added value, i.e. economic value added (EVA), the authors of Shad, Lai, Fatt, Klemeš, Bokhari (2019) states that a effective implementation of risk management has a significant positive impact on the overall performance of enterpises. But as the authors say, however, there are limited studies carried out on the implementation of risk management and how 
sustainability reporting could influence the performance of organisations through risk. Thus, many world-level organisations do not incorporate sustainability initiatives into their corporate strategy, while they should be an essential contribution to strategic management and corporate planning.

At the same time, the authors Arnold, Benford, Canada, Sutton (2015) mention in the elaborate article, that a strategic approach based on risk management in an organization improves flexibility and strengthens the coordination between flexibility and performance. The authors also argue that there is clear evidence that improved IT integration is the mechanism by which risk management strengthens both flexibility and performance in an organisation.

As Callahan\&Soileau (2017), including The Committee of Sponsoring Organizations of the Treadway Commission (COSO), the Entity Risk Management Framework (ERM) - (COSOERM) states, that the development of a risk assessment and management process at the level of the entire entity is designed to "provide reasonable assurance as to the achievement of the entity's objectives." In this respect, the authors conclude that entities with more developed risk management processes with higher levels of maturity of processes must achieve higher operational performance than those with less developed risks, i.e. with lower levels of process maturity.

So does Florio\&Leoni (2017) show that entities with advanced levels of risk management implementation are performing higher, both in financial performance and in terms of market assessment; and, as the authors claim, the authors here expect, on the one hand, that more efficient risk management systems lead to greater performance by reducing risk exposure, and on the other hand, the authors argue that the reverse causality between risk management and performance is not present in the short term.

We also believe that it is appropriate to state that in corporate governance, in any entity and in any type of entity, risk management is necessary because both in the company and in the environment in which it acts, there are uncertainties of the nature of threats in achieving objectives, or the nature of opportunities. Any manager needs to question how to manage threats, because otherwise by not achieving his goals, would disqualify, or capitalize on opportunities for the benefit of the organization, proving its effectiveness. If uncertainty is a daily reality, then the reaction to uncertainty must also become a permanent concern.

The above general motivation could justify the need to implement risk management by itself, but there are also some specific motivations, such as:

a) Risk management requires modification of management methods:

The managers of an organization shall not be confined to treating, every time, the consequences of events that have occurred. Handling the consequences does not improve the causes and therefore the already materialized risks will occur in the future also, as a rule, with a higher frequency and an increased impact on the objectives. Managers must adopt a reactive management method, which means that it is necessary to devise and implement measures that are likely to mitigate the risks. The future-oriented reaction enables the organization to control, within acceptable limits, the risks that have passed, that is the same as increasing chances of achieving its objectives. In conclusion, risk management excludes expectative and promotes action and foresight.

b) Risk management facilitates efficient implementation of the organization's objectives: Clearly knowing the threats allows a ranking of them depending on the situation of their materialization, the extent of the impact on the objectives and the costs of measures aimed at 
reducing the chances of developing or limit unwanted effects. Setting the positions constitutes the support of introducing a number of priorities in the allocation of resources, in most limited cases, following a "cost-benefit, analysis or, more generally, "effort-effect". It is essential that the organization focus its efforts towards what is really important, not to disperse its resources in non-critical areas for its purposes. At the same time, periodic risk review, as set out in standards, leads to reallocations of resources, in line with the modification of positions and, implicitly, the priorities. In other words, risk management involves concentrating resources in areas of current interest. In other words, risk management involves disposing resources in areas of current interest, and as the authors Caron, Vanthienen, Baesens (2013) manage the risks of enterprises are aimed at minimising the negative effects of uncertainty over objectives, while promoting the potential positive effects.

c) Risk management ensures the basic conditions for solid internal control:

If internal control is all the measures established by the management in order to obtain reasonable assurances that the objectives will be achieved, it follows that risk management is one of the important means to achieve this, because risk management is precisely pursuing the threat management that could negatively impact the objectives. From other point of view, if the strengthening of internal control is pursued, it is indispensable to implement the risk management. The action plan (activities to be carried out in order to achieve the objectives) must be seconded by the plan encompassing measures that mitigate the risk manifestation and by the plan of handling difficult situations (materialized risks).

However, in risk management, not the examples and techniques are the most important, but the attitude towards risk and this is, first of all, an aspect of the organizational culture that is formed over time, and not a result of imperative rules.

In another context, as Chen, Chuang, Huang, Shih (2019) states, adopting risk management in a company significantly helps the company improve its revenue and cost efficiency; and the analysis taken by authors in the financial industry subsector shows that banks and insurers adopting risk management generate more advantages in cost savings and the efficiency of their incomes.

So do the authors Eckles, Hoyt and Miller (2014), testing the hypothesis that the implementation and development of enterprise risk management (ERM) reduces the costs of businesses related to risk reduction, considers that the adoption and risk management represents a radical change in the paradigm from the traditional method of individual risk management to collective risk management, allowing entities that adopt risk management to prioritise coverage activities to the risks most contributing to the entity's total risk and optimise the assessment and selection of available hedging instruments. At the same time, the authors discover that entities that adopt risk management have a reduction in the volatility of stock return; it becomes stronger over time. In addition, the authors finally note that operational profits per unit of risk may increase after the adoption of the risk management by an entity.

Theorists in the field of risk recommend that it is very important to understand the culture of an entity Thus, as Griffiths said (2005, p. 21-22) there are several benefits of incorporating risk management into the culture of the organization, such us:

- greater attention to issues that really matter;

- reducing the time lost by the entity's leadership with disputes;

-fewer surprises;

- more satisfied customers; 
-protecting the reputation;

- more attention to do the right things in a correct manner;

- greater possibility of achieving the entity's objectives;

-fewer complaints;

-increased possibility of changing initiatives and achieve project benefits/drafted;

-risk-taking and more informed approach of decisions;

PICBE $\mid 187$

-support for innovation;

-lower insurance costs.

The objectives of approaching the risk management of any entity are to ensure that:

-risk management is a key part of the strategic management of the entity;

-there is a positive approach for taking the risk

-the risks are taken into account when taking any decision;

-opportunities are maximised by actively managing risks and threats that can hinder the emergence of success.

According to Ghiţă (2008, p. 219), in order to achieve these objectives, entities must consider the following approaches:

-clear liabilities will be set up and maintained, within all positions and departments, roles and reporting lines for risk management;

-introducing training programmes and opportunities for learning to ensure managers acquire and develop the skills and expertise necessary for risk management;

-risk analyses will be incorporated and considered part of decision-making, business planning and entity process revisions;

-the measures undertaken to manage individual risks will be appropriate to the potential occurrence and impact of these risks on the achievement of the entity's objectives;

-an updated register that can be easily accessible to all those who may need it will identify all strategic and operational risks, provide an estimate/retention/appreciation and registration of ongoing measures whose role is to manage these risks;

-performance of risk management activities will be measured in relation to company goals and objectives;

-an understanding of the risk and its management at all levels of the entity, with the majority partners and shareholders, combined with risk handling within the organisation, will be tried.

As the author said, for the management of an entity it is very important to identify risks, assess them and establish acceptable risk tolerance, in order of probability of occurrence and imminent impact that they may produce, by applying the appropriate control tools and analysis for their reporting.

In the same way, and in our view, given that from the point of view of an internal auditor, for example, the risk can be considered as the pulse of the entity, which may be perceived as a number of challenges, we believe that for any entity it is important that, before risk identification, it, the entity, has the objectives well established according to the actual and possible risks

In corporate governance, the possible or inherent risks are identified on the objectives and within them on activities or operations, and, as the author said, by exercising various forms of internal control limiting/diminishing risks, entities remain to manage only potential or residual risks.

DOI: $10.2478 /$ picbe-2020-0018, pp. 182-201, ISSN 2558-9652| Proceedings of the $14^{\text {th }}$ International Conference on Business Excellence 2020 
We consider it important to emphasize here the idea expressed by the authors Wang, Lin, Werner, Chang (2018) that in organizations where the risk management systems implemented are less performing, they can signal certain insufficient control mechanisms which, as the author said, may attract additional control by investors, thereby causing managers to resort to handling revenues, which may result in damage to the value of company in the long term.

Finally, in corporate governance, we are also of the opinion that the implementation of a risk management system contributes or should contribute to improving the performance of the entity, the company, but, in this respect, the management of the company is the identify risks, organise the risk management system and at the same time follow their progress.

In other terms, considering financing decisions and risk management in corporate governance, the structure of risk and profitability examples in financial literature underlines that, in the case of any investment, the expected profitability will depend mainly on the degree of undiversified risk associated with getting underlying asset. However, it is necessary to clarify that the market, through investors, will not remunerate all the risks assumed by an entity but only those that cannot be eliminated by prevention or primary techniques, as Zoicaş-Ienciu said (2013, p. 192) it goes without saying that investors will not encourage by financial support unforeseen entities or those that completely ignore the risks, putting in their decisions the emphasis on intuition, luck or resolutions at the right time. But, however, if desired, the entities are free to speculate on price, currency or interest rate developments. Moreover, there are many cases where such entities record a profitability above average but both theory and corporate experience have shown that this excess of profitability cannot be achieved consistently, being only the effect of the moment.

Furthermore, as the author also said, the voluntary assumption of risks that could otherwise be covered and avoided, will lead sooner or later to substantial losses, able to completely cancel any extra-profits.

In general, we can say that uncertainty and risk are part of the activity of any entity; but over time, performance, dynamic, or even survival differentiations at entity level come from the way the risk is managed. Before facing the issue of financial risks (currency, interest rate, systematic risk), an entity in general, but especially in corporate governance, in our opinion, must manage with priority the risks of an economic nature, which are more evident and more stringent: the evolution of demand for own goods or services, modification of consumer preferences and increased market competition, price dynamics for raw materials and finished products, lack of qualified personnel, etc. Once a mechanism for the management of these economic risks is implemented, attention can also be pointed on financial risks, less visible and often less aware.

In this respect, one of the most valuable contributions that financial management in an entity can have is to promote preventive behaviour; the usefulness of such an attitude becomes evident whenever there is a question of making an important decision. In such situations, nothing can substitute a competent analysis of potential risks resulting from the decision or finding preventive solutions before a direct confrontation with the damage. On the other hand, exposures to systemic risks cannot be prevented, in their case requiring the use of transfer techniques (insurance) or some coverage.

As a rule, financial risks are generated with the conduct of various transactions involving specific flows: acquisitions of immobilized assets in investments, bond issuance, bank loan contractions, commercial credit, export-import operations, mergers and acquisitions, etc. In most situations, the factors leading to the manifestation of financial risks come from the 
macroeconomic sphere: the sequence of economic cycle phases, monetary policy, fiscal policy, market developments, currency markets, social and political dissension, military conflicts, natural disasters, etc. Therefore, many of the generator factors are not under the control of entity management.

Thus, from a political perspective, on the factors that cause risk-like manifestation in general, and by referring to mitigating these risks, investigating risk mitigation strategies for multinational companies in emerging markets, Zhu\&Sardana (2020), based on the institutional perspectives and theoretical concept of March's to form a 'political coalition', the authors point out that risk mitigation at multinational companies cannot be limited to passive compliance and/or demonstration of good corporate behaviour, but should also extend to collective efforts by building a political coalition and working with company representatives to manage the potential of risk and achieve favourable results in complex institutional environments.

As Lundqvist (2015), quoting Kirkpatrick (2009), and entity's representatives have also made efforts to manage the risks of the enterprise (ERM) in response to faulty risk management systems and corporate governance. The author argues that risk management should be seen as a component of traditional risk management and risk governance, each having its own determinants, and that the implementation of risk governance is the active stage beyond the traditional risk management to risk management. The author, approaching the complexity of risk management, dividing it into its traditional risk management and risk governance components and investigating determining factors separately, but simultaneously, argues that the level of governance of risks in an entity is linked to the size of that entity, the different levers, dividends and the influence of the executive manager on the management board. This may suggest that corporate governance reasons, such as the need for governance, existing governance and executive manager's control over governance decisions, determine the decision to step towards the implementation of management risk. Finally, the author concludes that entities implement risk management in line with the wishes of the representatives to better govern the risk management system.

Moreover, Naciti (2019) states that one of the approaches to engaging the sustainable practices of companies also focuses on the composition of the board of directors, a composition that influences a company's financial performance. However, as the author states, cooperation between the composition of the boards and the sustainability practices of companies have not been empirically examined for a due period. As a result, focusing on the key characteristics of corporate governance - namely the diversity of the management board, the independence of the management board and the duality of executive management - the author discovers that entities with more diversity in the council and a separation between the functions of president and executive management lead to greater sustainability performance. At the same time, a greater number of independent managers lead to a lower performance of sustainability, and finally, as the author claims, the composition of the board affects an entity's sustainability performance. In another context, the authors Al-Hadi, Al-Yahyaee, Hussain, Taylor (2019) argue that, in corporate governance, the independence of managers and the dual roles of the general manager and the chairman of the board of directors reduce the importance and quality of market risk disclosure.

Otherwise, Kovermann\&Velte (2019) analysing the specific literature on the impact of corporate governance on corporate tax avoidance, applying a representatives oriented perspective, authors discover that various aspects of corporate governance, such as aligning 
incentives between management and representatives, board composition, ownership structure, capital market monitoring, auditing, enforcement and government relations, and pressure from other representatives have strong pressure/influence on the avoidance of corporation tax in particular. The authors point out that effective corporate governance mechanisms lead to the avoidance of taxes at the optimal entity level, so that, in the authors' opinion, good corporate governance does not only have the potential to increase avoidance more cost-effective entities, but also limits tax avoidance to a level where the risks that arise do not exceed the benefits.

In view of the above, we also believe that, especially in corporate governance, a concrete knowledge of the hedging techniques against the various risks is absolutely necessary for financial management within an entity, in volatile conditions of the contemporary business environment.

In any case, as the author states (Zoicaş-Ienciu, 2013, p. 192), given the complexity of the facts, risk management is not a subject that can be treated with indifference by an entity manager; this is because risk coverage solutions are often difficult to implement even when the risk is correctly identified beforehand and the steps to follow are precisely known.

Thus, we also agree with the author that a general conclusion can be drawn on the objective of risk management, namely to avoid the achievement of events that threaten the survival of the entity, and not to increase sales or reduce costs in no case being reccomended the removing of protection measures against the relevant risks, based on the cost savings, that expenditure is not less necessary than those of raw materials or salaries.

However, if there are more alternative risk coverage, we are also of the opinion that they need to be analysed in detail, and the solution that is least costly should be selected in the end. But, regardless of the situation, we can talk, including corporate governance, about a subordination of risk management to the fundamental objective of maximizing the worth of the entity.

In other terms, the express of risks at the entity level will affect both the size, stability and succession over time of future cash flows and the cost of the capital used to update them and as stated by Zoicaş-Ienciu (2013, p. 195) risk management, as part of financial management, aims at eliminating (as appropriate, reducing) the risk exposure of the entity but also reducing the likelihood of risk.

Basically, by transferring and covering the risk, the entity ensures that when its cash flow depreciates as a result of the risk, amounts will be collected from different third parties in subtractable values that compensate for the negative impact. This gives a certain degree of safety in maintaining financial parameters in the projected direction of management and preserves the market value of the entity; and in this respect any expense considered to cover the risk must be perceived as a common investment, the assessment of its opportunity being carried out by applying the classic criteria, as the author claims, only risk solutions leading to a positive net present value. At the same time, as authors, Ali , Liu, Su (2018) say in corporate governance, entities that are better governed are associated with a lower level of default risk and that association is stronger among entities with more opportunities growth.

Moreover, investment decisions play a key role in achieving any entity's strategic plan. Due to the involvement of a large amount of money, these decisions are the most important for all compay representatives. Thus, investigating the impact of corporate governance and investor confidence in corporate investment decisions in two different countries, Shahid\&Abbas (2019) confirms that there is a significant impact of investor confidence corporate investment decisions 
in both countries. The authors also argue that the level of investment is higher in entities with good corporate governance practices; the latter stimulating the impact of investor confidence on corporate investment decisions. Also, good corporate governance practices improve the monitoring function of board members, so they moderately control the interests of representatives, and that is why, as the authors claim, firm/determined managers make decisions effectively. However, the authors conclude that in the presence of rigorous corporate governance practices, however the impact of investor confidence on corporate investment is mitigated.

However, as the authors Bhaumik, Driffield, Gaur, Mickiewicz, Vaaler (2019), said, in corporate governance, foreign investment by emerging economy entities, led to improved governance capacities. Thus, these entities have also become supporters for policy reforms in their native country that have required the development of similar capacities for local entities.

Actually, by transferring and covering the risk, the entity shall ensure that when cash flow is reduced as a result of the risk manifestation, it will be charged from different third parties in similar amounts of decline, to compensate for the negative impact. This gives a certain degree of safety in terms of maintaining the financial parameters in the projected management direction and conserves the entity's market worth; and in this respect any expense made to cover the risk should be perceived as a regular investment, assessing its opportunity by applying the classical criteria, thus, as the author maintains, will only be implemented the non-risk solutions leading to a positive net present value.

With regard to the risk management process, it can be defined as the systematic application of management policies, procedures and practices for establishing the context, identification, analysis, evaluation, solution, monitoring and communication of risk. (Ghiţă, 2008, p. 239)

The risk management process is a systematic approach to risk analysis and solution. Thus, as Zoicaş-Ienciu says $(2013$, p. 197) there is a logical scheme in the process of risk management and which in our opinion and corporate governance presupposes the following steps:

Risk identification: consists of a systematic analysis of the entire entity's activity and identification of all relevant risk exposures. This stage involves the analysis of the entity's economic and financial-tax documents and records, the flow of operations and that of information, the division of risk questionnaires to employees, the verification of the existence of risks based on check-in lists as detailed as possible, more comprehensive etc. Here we consider it to be noted that in most cases the relevant exposures are evident, but a specialised analysis can reveal both important omissions and false exposures at risk.

Risk assessment and measurement: it is necessary to be able to appreciate the potential impact on the entity's financial situation. As a rule, in the case of each risk are considered several steps of materialization, but, as the author says, for each of these steps, two variables should be estimated, i.e. the probalility of realization and the costs of loss involved. We are also of the opinion that it would ideally be that the probability is numerically quantified but most of the time, management uses a qualitative assessment based on categories such as: quasi-null probability, low, medium, or quasi-safe probability. Following assessment the risks can also be classified according to the potential impact in critical risks (threatening the entity's survival), important (requires attracting funding) or negligible (minor losses that can be absorbed by the entity).

Selection of risk management techniques: is mainly a problem of managerial decision influenced by the entity's objectives and strategy, as well as the risk aversion of management; the 
criteria envisaged is the overall objective of maximising the value of the entity. As the author says there are four major categories of risk management techniques: avoidance (risk-generating situations are avoided; but the manoeuvre space for managers is reduced), prevention and control (preventive behaviour, conduct of jnvestments and training courses to avoid eventual losses), retention (risk is assumed and damage is covered by own resources accumulated in this respect in the form of reserves) and transfer (insurance, coverage, diversification).

PICBE | 192

Implementation: requires technical details related to the practical implementation of the selected management technique: development of prevention procedures, specific investments, accumulation of reserves, selection of insurer or stock market, contracts negotiation, hedging strategies formation etc.

Monitoring: consists of periodic verification and review of previously implemented risk decisions, identification of new exposures, change in probability of occurrence and character of risks, emergence of new techniques for cheaper coverage. At the same time, at this stage, we also believe that internal audit and control activities should also be considered to avoid fraud that may arise when employees responsible for the implementation of risk-covering techniques exceedes the tranzaction duties and limits.

But from the point of view of the system's functioning, in the same terms, also Ghita (2008, p. 239) states that risk management is a dynamic process, which in order to function involves the completion of a risk management cycle that incorporates several steps as follows:

- identification of risks, process involving all parts of expertise and responsability, which must contribute to the detection of all existing and possible risks, as well as their registration,

- assessment of the importance of the risks identified from the two elements, i.e. probability and impact,

- risk management, which implies knowledges regarding the importance of risks and the development of a strategy for their management. Moreover, the purpose of this activity should be to ensure that all key risks are under control,

- the risk assessment requires a supervision of the entire risk management process and the outcome of this activity should contribute to updating the risk management strategy applied throughout the organisation.

The stages of the risk management process in corporate governance involve the achievement of key activities in a logical succession, as follows:

-risk identification,

-risk assessment;

-risk control;

-risk Analysis and reporting. (Ghiţă, 2008, p. 245)

\section{Identification of risks in corporate governance}

In an organisation, in the ideal conditions where all risks should be identified and recorded, a major concern of the organisation, it is precisely the identification of risks. In this context, as the Ghiţă said (2008, p. 245), although there is no documentary pattern for risk identification, this activity is a first step in setting up a risk profile for their analysis within the framework of the organizations. 
Thus, the identification of risks involves two components, i.e. the initial identification of the risks on each objective, but also a continuous identification of new risks, those due to changes in the organisation or those that arise due to changes in legislation.

We are also of the same opinion as the author, namely that the risks must be related to the objectives and can be evaluated and prioritised, in close connection with the objectives, starting from individual objectives and continuing with the entire objectives of the entity. At the same time, for all identified risks, it is necessary to establish the responsible persons who will continuously manage and monitor those risks; while requiring the risk officer to have the necessary authority to ensure effective risk management.

The approach to risk identification can be achieved as follows:

- By self-assessment of risks by persons involved in achieving those objectives/activities on hierarchical levels, by setting the risks that they frequently meet. Thus, self-assessment can be achieved through a documentary approach, on the basis of questionnaires or by setting up working groups on departments or activities, and to which should take part certain specialised persons, who possess the skills necessary to identify the different risks. As the aforementioned author said, a strong point of this approach is that those responsible for risks become more conscious when they are involved in the risk identification activity.

- By analysing the risks to be carried out by a department which has been specially set up within the entity or even by an external team, named to assess all operations and activities of the organisation in relation to its objectives and to which to attach appropriate risks. We are also of the opinion that in the situation of applying this approach it is important that the activities of the department or team do not undermine the understanding of responsibility in managing and monitoring risks by line management and mainly by responsible risk responsible persons.

However, as Ghiţă said (2008, p. 246), it resulted from the practice that a combination of the two approaches would be more effective for organisations, since this combination could reveal significant differences in perception of the risks which once being handled insures a proper management of those.

As the author said the risks to which the entity is exposed can be grouped in several categories.

Griffiths (2005, p. 22) considers that the most common risk categories are the following:

Strategic risks - are risks that affect the goals and objectives of the organisation in the medium and long term, and the management of these risks is usually the responsibility of the Risk Management Committee (RMC). Strategic risks include the following risks:

-political: Failure to fulfil government policy;

-economic: Implications of changes in the economy (inflation, interest rates, etc.);

-social: the inability to have responsibility for the effects of changes in demographic and socioeconomic tendencies and the inability to reflect them in the company's objectives,

- risks concerning the clients: failure to identify current and changing clients needs.

Operational risks - are the risks that managers and management will encounter in daily work, namely:

- competition risks: failure to confer value on money, quality of products, etc,

- physical/material risks hazards related to fires, security, accident prevention, health and safety (buildings, vehicles, machinery and equipment, etc.); 
- contractual risks: failure of contractual parties to provide services or products on time, at the cost or specifications set out.

Financial risks - are significant risks that will be continously considered by the management and which may be failures in financial planning, budgetary control, management of funds and respectively incorrect, inadequate or inaccurate monitoring and reporting or a delayed one.

Reputation or brand risks - are those risks associated with the media area and any actions or non-actions that may affect the entity, trademark or reputation of the company.

Information and IT-related risks - are risks related to IT technology that are in constant motion, namely:

-technological risks: lack of confrontation capability with the rhythm and magnitude of changes, lack of ability to use technology in response to changing needs, internal failures of technological nature, failures in the acquisition of technology, etc.,

- physical risks related to IT - failures of different IT equipment, telephony, etc.

Personnel risks:

- occupational risks: failures caused by lack of financial decisions, lack of specialised staff, lack of consultations on certain developments, etc.;

- leadership and management risks: lack of key personnel or inability to provide on its part, inability to ensure adequate professional training, etc.

From the point of view of identifying potential risks Ghiţă (2008, p. 247) mentions the following methods that can be used:

- workshops, different work meetings;

-planning stages;

-analysing past receivables and other losses;

- analyze past incidents/failures;

-health and safety inspections;

-beginners training;

- past acchievements review;

- making feedback between management and different clienhts/vendors, etc.

As the author said, in practice there are other categories of risks considering certain criteria, namely:

probability of occurrence:

- potential risks, which are likely to occur if effective control is not established to prevent and/or correct them;

- possible risks presented by those potential risks for which management has not undertaken the most effective measures to eliminate or mitigate their impact;

nature of risks:

- strategic risks relating to the realisation of misguided actions related to organisation, resources, environment, IT endowment, etc. 
- information risks, regarding approach of unsafe or non-performing systems for the processing of information and for reporting;

- financial risks related to the loss of financial resources or the accumulation of unacceptable liabilities;

the nature of the activities and operations carried out within the entities: legislative risks, financial risks, operational risks, commercial risks, legal risks, social risks, image risks, environmental risks, risks regarding information security, etc.

entities specificities: general risks (on economic situation, organisation and management attitude, etc.), risks related to the nature of specific activities/processes/operations, risks of designing and functioning systems, risks related to elaborating and updating procedures.

In conclusion, although there are other risk classifications, we are also of the opinion that in practical activity of the entities in general and corporate governance in particular, the most important elements on risks still remain those related to;

-likelihood of risk and

-the impact level, namely the seriousness of the consequences and their period, where those risks would occur.

\section{Risk Assessment in corporate governance}

It is the stage when assessing the importance of risks that have been identified and should gravitate around the two-dimensional impact and vulnerability components.

The majority of risks are subject to a numerical diagnosis, in particular financial risks or financial connotations, but there are also risks whose assessment has a more subjective perspective, for example the risk of image, reputation risk, brand risk, etc.. (Ghiţă, 2008, p. 250)

As the author said, the risks, once evaluated, will lead to the setting of their priorities within the organisation. At the same time, the major risks, namely the highest priority, must be permanently envisaged at the highest level of the organisation because the risk priorities change during the management process as they are handled.

Moreover, also in corporate governance, we are also of the opinion that risk assessment is part of the operational process and must identify and analyse internal and external factors that could negatively affect the objectives of the organisation; and risk assessment must cover the entire range of risks within the entity. In these conditions, it is necessary to cover all hierarchical levels in an organisation, especially the top ones.

In conclusion, in corporate governance the activity of risk assessment is an essential component of risk management, and as a result the evaluation activity should be carried out at least once a year to update the analysis risks, but also to identify new risks.

\section{Risk control in corporate governance}

Risk control is carried out in order to transform uncertainties into an advantage for the organisation, limiting the level of threats.

Ghiţă (2008, p. 256) states that risk control involves carrying out activities such as: risk toleration, risk management, risk shifting, cessation of activities and benefit from opportunities.

\section{Risk tolerance}

DOI: $10.2478 /$ picbe-2020-0018, pp. 182-201, ISSN 2558-9652| Proceedings of the $14^{\text {th }}$ International Conference on Business Excellence 2020 
Certain risks may be accepted without any action being required. It should be considered that, in the event of risks, even if they are hardly tolerated, there is always no possibility to act to be remedied as a result of certain costs that may be disproportionate.

\section{Risk handling}

In general, the the risks in corporate governance are controlled in order to be handled; thus, while the organisation carries out the activities that have generated the risks, as a rule, a certain control system is installed that is intended to maintain risks within acceptable limits because unhandled or unefficient handle of risks, could cause a corporate crisis leading to significant losses.

In practice, in coporative governance, we also found that the following categories of verification tools are used to handle risks:

- when pursuing an undesirable result not to materialise or to limit the effects of unwanted risks that could materialize;

- corrective verification tools - the aim being to correct the unwanted results that have materialised and is a way to recover damage or losses;

- directional verification tools - designed to ensure the achievement of a particular result, they are essential when they want the effects of a certain undesirable risk that may materialise to be oriented in a certain tolerable direction by the organization;

- identification control tools - the aim being to identify the newly unwanted situations that have taken place within the organisation, and the implementation of such tools being subsequent to events/risks, as a rule, some damage or losses incurred.

\section{Risks transfer}

In corporate governance, this option is particularly beneficial in the case of financial or property risks and can be made by insurance or payment of a third party that would make another way of taking risks. Transferring risks by either reducing risk exposure or because another organisation is more capable or specialized in managing such risks. We mention that there are also certain risks that cannot be transferred or are wholly non-transferable, such as reputational risks, organization brand, etc.

\section{Termination of activities}

In corporate governance certain risks may be eliminated or may be maintained within reasonable limits by reducing activities or by abolishing them.

\section{Benefit from opportunities}

According to Ghiţă (2008, p. 259) this option should be taken into account when a risk is tolerated, handled or transferred, where there are the following opportunities: -simultaneously with the reduction of events, the risk arises as an opportunity; -some circumstances that, not generating risks, even provide opportunities;

In conclusion, in view of the foregoing, we are also of the opinion that, in the situation where certain verification instruments are implemented in corporate governance, it must be pursued that these instruments implemented provide reasonable assurance for maintenance of default risks and losses in the espected risk appetite. But also, given that the purpose of a control is to reduce risks or eliminate them and maintain them in the area of acceptance of the 
organisation and knowing, at the same time, that each verification instrument implemented requires certain costs, we are also of the opinion that before a particular verification instrument is implemented, a more detailed analysis should be considered in relation to the risks it controls and assesses each control instrument that is intended to be implemented.

Under these conditions, in corporate governance, the responsibility for organising activities on risk management and administration is the responsibility both for organization's management and the separate management of each entity as part of the group.

\section{Risk analysis and reporting in corporate governance}

In corporate management, the risk supervision activity is necessary to monitor the evolution of risk profiles and to ensure that the risk management activity is appropriate and is achieved through different risk review processes. (Ghiţă, 2008, p. 260).

In this respect, as the author also said, it is necessary that the risk analysis be carried out periodically, at least annually, in order to assess the persistence of the risk, namely possible changes in the impact and likelihood, the emergence of new risks, with the scope to report these risk developments which influences certain priorities and provides information on the effectiveness of control.

We are also of the opinion that the general risk management process must undergo periodic examinations in order to ensure its functionality, the existence of a risk system with an appropriate frequency and setting out mechanisms for warning of higher management levels on risk developments or the occurrence of other unforeseen risks.

But here it should be noted that the risk management process and the analysis activity or review of risks are two distinct activities that do not substitute one another.

In corporate governance the main tools and techniques used in the risk analysis process are:

- risk self-assessment, which is carried out for the purpose of assessing the preservation of the risk profile across the organisation and must be carried out by each employee.

- line management reporting responsible for risk management, to higher management, on the activities they have undertaken, at least annually, at the time of the financial year, in addition to the quarterly and half-yearly, to update the risk register and the management control system, which maintains an appropriate level of functionality operational procedures;

- specialised teams for the revision and updating of the general risk management process, which analyse the activity of line management regarding their responsibilities in the field of activity which coordinates regarding risks and management control systems.

- constitution of risk committees, which must be established by the management - the board of directors and which will have the following roles assigned:

- the risk committee, established as an adminsitration board committee, consisting of nonexecutive members, with tasks to monitor their risks and developments, which gives an opinion on the risk management process on the organisation, tasks which were otherwise responsability of the audit committee.

- the risk committee, established as a forum of executive directors, who have responsibilities in the field of risk management and where they share their experiences with a view to developing their own risk management measures and ensuring their effectiveness of managing.

DOI: 10.2478/picbe-2020-0018, pp. 182-201, ISSN 2558-9652| Proceedings of the $14^{\text {th }}$ International Conference on Business Excellence 2020 
However, as Ghiţă said (2008, p. 262), this way of organising the risk committees does not exclude non-executive persons in its structure, where the tasks of risk monitoring and their management process it remains at the level of the audit committee within the organisation, which must provide independent assurances regarding the risk management system within it, of the organisation.

In view of the above, in conclusion, according to Griffiths (1998, p. 28-29), the organisation must pursue the impact of risk management activities and the success of the risk management strategy using the following criteria, analysis or review of risks, such as those presented in the following figure:

Table 1. Risk monitoring

\begin{tabular}{|c|c|c|}
\hline $\begin{array}{l}\text { Risk Analysis } \\
\text { Criteria }\end{array}$ & Refferences & Comment \\
\hline $\begin{array}{l}\text { Integrating risk } \\
\text { management into } \\
\text { the organization's } \\
\text { culture and } \\
\text { increasing its } \\
\text { awareness }\end{array}$ & $\begin{array}{l}\text { Leading persons acknowledge their role and } \\
\text { responsibility for the implementation of risk } \\
\text { management in the areas in which they operate. } \\
\text { Number of decision-making reports demonstrating } \\
\text { a risk analysis. Audit and inspection responses. }\end{array}$ & $\begin{array}{l}\text { By auditing reports and } \\
\text { documents highlighting } \\
\text { decisions. By auditing the } \\
\text { replies. }\end{array}$ \\
\hline $\begin{array}{l}\text { Oportunity of } \\
\text { modification }\end{array}$ & $\begin{array}{l}\text { The post-factum analysis, namely how major } \\
\text { modificatins and other projects were managed. }\end{array}$ & \\
\hline $\begin{array}{l}\text { Minimising losses, } \\
\text { accidents and } \\
\text { conflicts }\end{array}$ & $\begin{array}{l}\text { Number and period of the production process } \\
\text { interruptions. } \\
\text { Complaints/grievances, claims etc. } \\
\text { Level of the prescribed delays/liabilities. }\end{array}$ & $\begin{array}{l}\text { Measures the response and } \\
\text { performance of recovery as } \\
\text { well as frequency. Informed } \\
\text { of the existence of strategies } \\
\text { and processes. }\end{array}$ \\
\hline $\begin{array}{l}\text { Existence of a risk } \\
\text { management } \\
\text { pattern }\end{array}$ & $\begin{array}{l}\text { Feedback from management. } \\
\text { Compliance with standards }\end{array}$ & \\
\hline $\begin{array}{l}\text { Minimising risk } \\
\text { costs }\end{array}$ & $\begin{array}{l}\text { Annual insurance premiums. } \\
\text { Level of reserves. } \\
\text { Uninsured losses. } \\
\text { Cost of management and project }\end{array}$ & $\begin{array}{l}\text { The overlaps of budget and } \\
\text { capital allocated to the } \\
\text { project, fraud, prescriptions, } \\
\text { claims, premiums, are } \\
\text { incorporated. }\end{array}$ \\
\hline
\end{tabular}

Source: Griffiths (1998, p. 28-29)

\section{Conclusion}

Over time, risk management should be incorporated into the organisation's operations and procedures and become a component of its culture but also its decision-making processes and structures, with substantial possibilities for performance monitoring. (Ghiţă, 2008, p. 240)

Also in corporate governance when carrying out the risk management implementation process a special role lies with the audit committee which rigorously needs to assess the contribution of risk management to streamlining operations and increasing the values of the organization.

In another context, according to authors, as, Pérez-Cornejo, De Quevedo-Puente, Delgado-García (2019), corporate reputation research has generally claimed that the reputational 
risk or risk of loss of a company's reputation stem from all company's risks. As companies use business risk management systems (ERM) to manage all their risks, after analysing the quality effect of the risk management system on corporate reputation, the authors concluded that the risk management system is a useful tool for managing the corporate reputation.

In addition, as the audit committees are responsible for supervising risk management systems, following consideration of the effect of the characteristics of the audit committee (i.e. independence, knowledge and diligence of independent members) corporate reputation, through their effect on the quality of the risk management system, the authors also concluded that the independence of the audit committee improves corporate reputation through the risk management system. Finally, the authors find a generally positive coordination between the educational level of independent managers of the audit committee and the quality of the risk management system. These results, in the authors' opinion, provide clear evidence that risk management systems are platforms for corporate reputation management and suggest the importance of the audit committee as a supervisor of the risk management system and as guarantor of corporate reputation.

Good risk management increases the confidence that stakeholders have in corporate governance within an organization and the latter's ability to achieve its objectives. Moreover, risk management is an essential component for the success of the organization and will have to become an inherent part of its functioning and to be in the permanent attention of the management board.

\section{References}

Books:

Ghiţă, M., (2008). Guvernanţă corporativă. Bucureşti: Editura Economică.

Griffiths, P., (1998). Risk-Based Auditing. Adershot, England: Gower Publishing Limited. Griffiths, P., (2005). Risk-Based Auditing. Burlington, USA: Gower Publishing Company.

Zoicaş-Ienciu, A., (2013). Elemente de management financiar. Cluj-Napoca: Presa Universitară Clujeană.

Articles:

AL-HADI, Ahmed, AL-YAHYAEE, Khamis, Hamed, HUSSAIN, Syed, Mujahid, TAYLOR, Grantley, (2019), Market risk disclosures and corporate governance structure: Evidence from GCC financial firms, The Quarterly Review of Economics and Finance, Volume 73, Pages 136-150.

ALI, Searat, LIU, Benjamin, SU, Jen, Je, (2018), Does corporate governance quality affect default risk? The role of growth opportunities and stock liquidity, International Review of Economics \& Finance, Volume 58, Pages 422-448.

ARNOLD, Vicky, BENFORD, Tanya, CANADA, Joseph, SUTTON, Steve, G., (2015), Leveraging integrated information systems to enhance strategic flexibility and performance: The enabling role of enterprise risk management, International Journal of Accounting Information Systems, Volume 19, Pages 1-16.

BHAUMIK, Sumon, DRIFFIELD, Nigel, GAUR, Ajai, MICKIEWICZ, Tomasz, VAALER, Paul, (2019), Corporate governance and MNE strategies in emerging economies, Journal of World Business, Volume 54, Issue 4, Pages 234-243. 
BROMILEY, Philip, McSHANE, Michael, NAIR, Anil, RUSTAMBEKOV, Elzotbek, (2015), Enterprise Risk Management: Review, Critique, and Research Directions, Long Range Planning, Volume 48, Issue 4, Pages 265-276.

BROSSMAN, Charles, (2016), 9 - Enterprise risk management and its relation to travel risk management, Building a Travel Risk Management Program - Traveler Safety and Duty of Care for Any Organization, Pages 157-165.

PICBE $\mid 200$

CALLAHAN, Carolyn, SOILEAU, Jared, (2017), Does Enterprise risk management enhance operating performance?, Advances in Accounting, Volume 37, Pages 122-139.

CARON, Filip, VANTHIENEN, Jan, BAESENS, Bart, (2013), A comprehensive investigation of the applicability of process mining techniques for enterprise risk management, Computers in Industry, Volume 64, Issue 4, Pages 464-475.

CHEN, Yu-Lun, CHUANG, Yi-Wei, HUANG, Hong-Gia, SHIH, Jhuan-Yu, (2019), The value of implementing enterprise risk management: Evidence from Taiwan's financial industry, The North American Journal of Economics and Finance, Article 100926.

ECKLES, David, L., HOYT, Robert, E., MILLER, Steve, M., (2014), Reprint of: The impact of enterprise risk management on the marginal cost of reducing risk: Evidence from the insurance industry, Journal of Banking \& Finance, Volume 49, Pages 409-423.

FARRELL, Mark, GALLAGHER, Ronan, (2019), Moderating influences on the ERM maturityperformance relationship, Research in International Business and Finance, Volume nr. 47, pag. 616-628.

FLORIO, Cristina, LEONI, Giulia, (2017), Enterprise risk management and firm performance: The Italian case, The British Accounting Review, Volume 49, Issue 1, Pages 56-74.

FRASER, John, R.,S., SIMKINS, Betty, J., (2016), The challenges of and solutions for implementing enterprise risk management, Business Horizons, Volume 59, Issue 6, Pages 689-698.

GORDON, Lawrence, A., LOEB, Martin, P., TSENG, Chih-Yang, (2009), Enterprise risk management and firm performance: A contingency perspective, Journal of Accounting and Public Policy, Volume 28, Issue 4, Pages 301-327.

LANDONI, Matteo, (2020), Knowledge creation in state-owned enterprises, Structural Change and Economic Dynamics, Volume 53, Pages 77-85.

LUNDQVIST, Sara, A., (2015), Why firms implement risk governance - Stepping beyond traditional risk management to enterprise risk management, Journal of Accounting and Public Policy, Volume 34, Issue 5, Pages 441-466.

KOVERMANN, Jost, VELTE, Patrick, (2019), The impact of corporate governance on corporate tax avoidance - A literature review, Journal of International Accounting, Auditing and Taxation, Volume 36, Art. 100270.

NACITI, Valeria, (2019), Corporate governance and board of directors: The effect of a board composition on firm sustainability performance, Journal of Cleaner Production, Volume 237, Art. 117727.

OLIVA, Fábio, Lotti, (2016), A maturity model for enterprise risk management, International Journal of Production Economics, Volume 173, Pages 66-79.

PÉREZ-CORNEJO, Clara, De QUEVEDO-PUENTE, Esther, DELGADO-GARCÍA, Juan Bautista, (2019), How to manage corporate reputation? The effect of enterprise risk management systems and audit committees on corporate reputation, European Management Journal, Volume 37, Issue 4, Pages 505-515. 
SHAD, Muhammad, Kashif, LAI, Fong-Woon, FATT, Chuah Lai, KLEMEŠ, Jiří, Jaromír, BOKHARID, Awais, (2019), Integrating sustainability reporting into enterprise risk management and its relationship with business performance: A conceptual framework, Journal of Cleaner Production, Volume 208, Pages 415-425.

SHAHID, Muhammad, Sadiq, ABBAS, Muhammad, (2019), Does corporate governance play any role in investor confidence, corporate investment decisions relationship? Evidence

PICBE | 201 from Pakistan and India, Journal of Economics and Business, Volume 105, Art. 105839.

WANG, Teng-Shih, LIN, Yi-Mien, WERNER, Edward, M., CHANG, Hsihui, (2018), The relationship between external financing activities and earnings management: Evidence from enterprise risk management, International Review of Economics \& Finance, Volume 58, Pages 312-329.

WU, Desheng, OLSON, David, L., DOLGUI, Alexandre, (2015), Decision making in enterprise risk management: A review and introduction to special issue, Omega, Volume 57, Part A, Pages 1-4.

ZHU, Ying, SARDANA, Deepak, (2020), Multinational enterprises' risk mitigation strategies in emerging markets: A political coalition perspective, Journal of World Business, Volume nr. 55, Issue 2, Article 101044.

www.mfinante.ro 